\title{
ANALISA KEBUTUHAN PRODUK GENERAL LIGHTING DI PT X (DISTRIBUTOR LAMPU LED) DENGAN METODE PERAMALAN
}

\author{
Kurniyanto Bayu Anggoro ${ }^{1)}$, Popy Yuliarty $^{2)}$,Rini Anggraini ${ }^{3)}$ \\ ${ }^{1,2)}$ Program Studi Teknik Industri, Fakultas Teknik, Universitas Mercu Buana Jakarta \\ ${ }^{3)}$ Program Studi Teknik Industri, Fakultas Teknik,Universitas Mercu Buana Jakarta \\ Email : aa_bayu28@yahoo.com
}

\begin{abstract}
Abstrak : PT. X selaku distributor resmi lampu LED, menjual produk-produk general lighting, dengan selalu berusaha memberikan pelayanan yang optimal kepada pelanggan. Untuk memenuhi kebutuhan konsumen akan produk-produk general lighting, PT.X masih belum memiliki sistem stok. Oleh karena itu konsumen harus bersedia menunggu sesuai lead time dari produk yang akan mereka beli. Tujuan penelitian ini adalah untuk mengetahui metode peramalan yang tepat untuk menentukan jumlah kebutuhan stok produk. Metode yang digunakan adalah metode peramalan Linea Regression. Hasil penelitian adalah didapatkan hasil peramalan untuk bulan Juli 2020 untuk ke 2 item produk adalah sebesar 32 dan 54 unit
\end{abstract}

Kata kunci : kebutuhan, peramalan, Linear Regression, Exponential Smoothing, Moving Average

\section{PENDAHULUAN}

Pada dunia jasa distribusi barang, ketersedian stok barang adalah salah satu faktor yang dapat memberikan keunggulan untuk menarik konsumen. Bukan hanya persoalan harga. Sebagai contoh saat mencari gadget type A di marketplace, banyak penjual atau distributor yang menawarkan dengan harga dan ketersediaan barang yang bervariasi. Disinilah terjadi persaingan, karena dimana selain harga, faktor lain yang menjadi pertimbangan sebelum konsumen membeli suatu barang adalah ketersediaan spare parts (Sutardi dan Budiasih, 2007). Tuntutan konsumen terhadap suatu produk tidak terbatas pada harga dan kualitas saja tetapi juga pada pelayanan yang diberikan (Kushartini dan Almahdy, 2016). PT. X selaku distributor resmi lampu LED, menjual produkproduk general lighting, dengan selalu berusaha memberikan pelayanan yang optimal kepada pelanggan. Untuk memenuhi kebutuhan konsumen akan produk-produk general lighting, PT.X masih belum memiliki sistem stok. Oleh karena itu konsumen harus bersedia menunggu sesuai lead time dari produk yang akan mereka beli. Jika dilihat dari periode yang lalu, berikut historis penjualan produk general lighting PT. X 2019-2020.

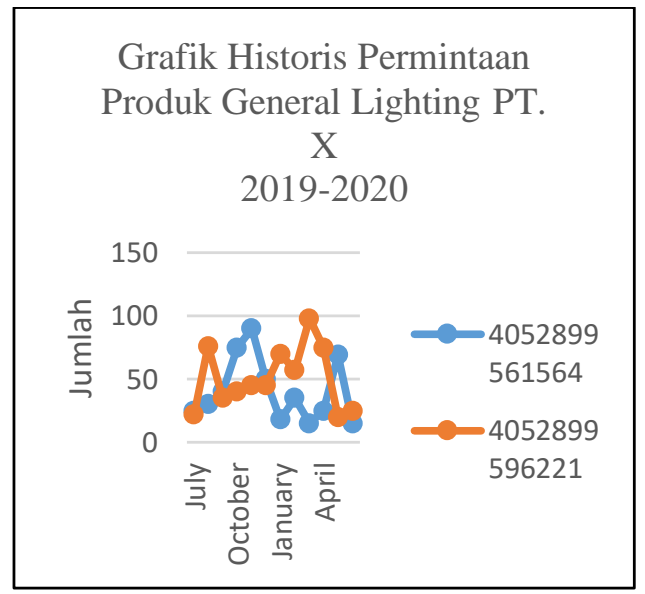

Gambar 1 Grafik Historis Permintaan Produk General Lighting PT. X 2019-2020

Dilihat dari jumlah yang fluktuatif akan kebutuhan produk general lighting dan dikarenakan belum memiliki sistem stok, maka akan dibuat analisa kebutuhan produk general lighting dengan metode peramalan. Menurut Gaspesz Peramalan adalah kegiatan memperkirakan tingkat permintaan produk di waktu yang akan datang dengan menggunakan data yang tersedia saat ini (Garpersz,V 2002). Metode ini merupakan salah satu metode yang akurat, yang dapat digunakan dalam membuat analisa persediaan. 
Tujuan dari penelitian ini adalah :

1. Mengetahui metode peramalan yang dapat digunakan untuk menentukan jumlah kebutuhan stok produk general lighting di PT.X.

2. Mengetahui kebutuhan jumlah stok produk general lighting di PT.X untuk periode kedepan

Persediaan didefinisikan sebagai barang yang disimpan untuk digunakan/dijual pada periode mendatang dan persediaan dapat berbentuk bahan baku yang disimpan untuk diproses, komponen yang diproses, barang dalam proses dan barang jadi yang disimpan untuk dijual (Hendra, 2009; Ramadhanti, \& Ariyanti, 2017).

Pengendalian persediaan merupakan kegiatan yang berhubungan dengan perencanaan, pelaksanaan, dan pengawasan penentuan kebutuhan material sedemikian rupa sehingga disatu pihak kebutuhan operasi dapat dipenuhi pada waktunya dan dilain pihak investasi persediaan material dapat ditekan secara optimal. Persediaan merupakan suatu hal yang tak terhindarkan (Baroto : 2002). Untuk menyelesaikan masalah di masa datang yang tidak dapat dipastikan, orang senantiasa berupaya menyelesaikannya dengan model pendekatan-pendekatan yang sesuai dengan perilaku aktual data, begitu juga dalam melakukan peramalan. Peramalan (forecasting) permintaan akan produk dan jasa di waktu mendatang dan bagian-bagiannya adalah sangat penting dalam perencanaan dan pengawasan produksi. Selain itu perusahaan juga dituntut untuk dapat memuaskan konsumen dengan cara menyelesaikan pesanan konsumen tepat pada waktunya (Dewi dan Saroso, 2016).

\section{METODE}

Tahapan dalam penelitian ini dapat dilihat pada Gambar 2 berikut ini :

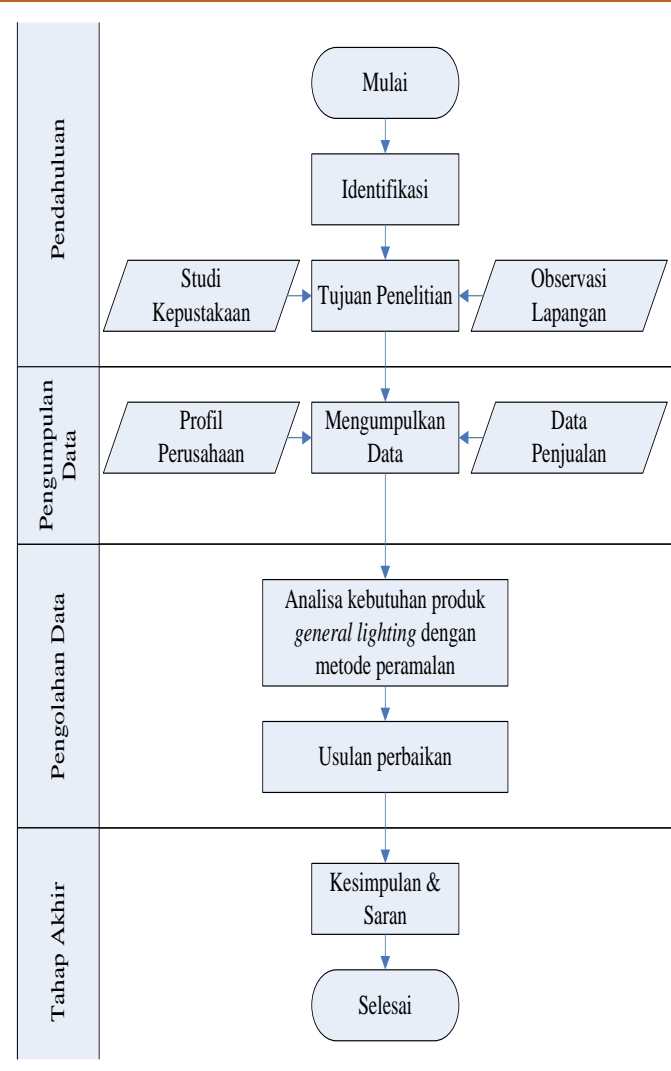

Gambar 2. Tahapan Penelitian

Metode peramalan dapat diklasifikasikan menjadi 2 macam yaitu:

1. Metode Kuantitatif. Metode Kuantitatif merupakan metode peramalan yang menggunakan data historis yang diakumulasikan dalam periode waktu tertentu. Macam-macam model peramalan kuantitatif antara lain:

a. Model Deret Berkala (Time Series). Metode peramalan yang didasarkan atas penggunaan analisa pola hubungan antara variabel yang akan diperkirakan dengan variabel waktu, yang merupakan deret waktu.

b. Model Kausal. Metode peramalan yang didasarkan atas penggunaan analisa pola hubungan antara variabel lain yang mempengaruhinya, yang bukan waktu yang disebut metode korelasi atau sebab akibat. Model kausal terdiri dari:

- Metode regresi dan korelasi

- Metode ekonometri

- Metode input dan output 
2. Metode Kualitatif. Metode peramalan yang didasarkan atas data kualitatif masa lalu. Hasil peramalan yang ada tergantung pada orang yang menyusunnya, karena peramalan tersebut sangat ditentukan oleh pemikiran yang bersifat intuisi, judgement (pendapat) dan pengetahuan serta pengalaman dari penyusunnya.

Pada penelitian ini akan menggunakan metode kuantitatif dengan model Deret Berkala (time series), karena data yang dimiliki adalah data historis dan grafik dari data tersebut menunjukkan pola permintaan yang memiliki hubungan terhadap waktu.

Pada penelitian ini, penulis menggunakan jenis peramalan Linear Regression, Exponential Smoothing, dan Moving Average. Pemilihan metode ini dikarenakan metode linear regression merupakan peramalan yang menunjukkan adanya kecenderungan menaik dari waktu ke waktu, sedangkan exponential smoothing merupakan peramalan yang menggunakan data historis jangka pendek untuk mendapatkan peramalan untuk permintaan yang terbaru, dan moving average dikarenakan tidak dipengaruhi trend atau seasonal.

\section{HASIL DAN PEMBAHASAN}

Pada tahap ini. Pengumpulan dan pengolahan data dilakukan untuk mengetahui kebutuhan permintaan produk.

Data permintaan general lighting di tahun 2019-2020 di PT.X dapat dilihat pada Tabel 1 berikut ini :

Tabel 1 Data Historis Permintaan Produk General Lighting 2019-2020

\begin{tabular}{|c|l|c|c|}
\hline \multirow{3}{*}{ Year } & SKU & 405289 & 405289 \\
\cline { 2 - 4 } & & 956156 & 959622 \\
& Month & 4 & 1 \\
\hline \multirow{2}{*}{2019} & July & 25 & 22 \\
\cline { 2 - 4 } & August & 30 & 76 \\
\hline
\end{tabular}

\begin{tabular}{|l|l|c|c|}
\hline \multirow{1}{*}{} & September & 40 & 35 \\
\cline { 2 - 4 } & October & 75 & 40 \\
\cline { 2 - 4 } & November & 90 & 45 \\
\cline { 2 - 4 } & December & 50 & 45 \\
\hline \multirow{4}{*}{2020} & January & 18 & 70 \\
\cline { 2 - 4 } & February & 35 & 57 \\
\cline { 2 - 4 } & March & 15 & 98 \\
\cline { 2 - 4 } & April & 25 & 75 \\
\cline { 2 - 4 } & May & 69 & 20 \\
\cline { 2 - 4 } & June & 15 & 25 \\
\hline
\end{tabular}

Sumber: Pengumpulan Data

Dari data pada Tabel 1 di atas dapat dilihat permintaan ke 2 jenis produk general lighting pada tahun 2019 sd 2020.

Data ini kemudian dilakukan peramalan permintaan untuk ke dua item dan hasil perhitungan peramalannya dapat dilihat pada Tabel 2. Peramalan kebutuhan material ini menggunakan tiga metode peramalan, yaitu metode Linear Regression, Exponential Smoothing, dan Moving Average yang dalam perhitungannya menggunakan bantuan software Microsoft Excel. Setelah hasil peramalan diperoleh, kemudian penulis menghitung kesalahan peramalan dengan menggunakan perhitungan Mean Absolute Deviation, Mean Squared Error, dan Mean Absolute Percentage Error. Khusus dalam metode Exponential Smoothing, peramalan menggunakan nilai konstanta pemulusan yang menghasilkan nilai Mean Absolute Deviation terkecil. Oleh karena itu perlu melakukan percobaan peramalan dengan mengguanakan nilai konstanta pemulusan dari 0.1-1, dan digunakan nilai konstanta pemulusan yang menghasilkan nilai Mean Absolute Deviation terkecil.

Perhitungan peramalan untuk ke 2 Item di atas dapat dilihat pada Tebel 2 sampai dengan Tabel 5 di bawah ini : 
Tabel 2. Hasil Perhitungan Peramalan dan Error Item SKU 4052899561564

\begin{tabular}{|c|c|c|c|c|c|c|c|c|c|c|c|c|c|c|c|c|c|c|}
\hline \multicolumn{19}{|c|}{4052899561564} \\
\hline \multirow[b]{2}{*}{ 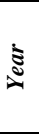 } & \multirow[b]{2}{*}{ 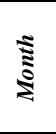 } & \multirow[b]{2}{*}{ 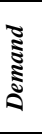 } & \multirow[b]{2}{*}{$\frac{2}{2}$} & \multicolumn{5}{|c|}{ Linear Regression } & \multicolumn{5}{|c|}{ Exponential Smoothing (a 0.1) } & \multicolumn{5}{|c|}{ Moving Average (3 Periode) } \\
\hline & & & & 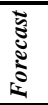 & $\stackrel{\grave{1}}{\grave{1}}$ & 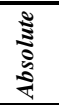 & 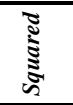 & $\begin{array}{l}\bar{\vdots} \\
\frac{1}{12} \\
8\end{array}$ & 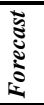 & 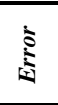 & 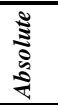 & 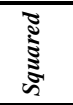 & $\begin{array}{l}\overline{\bar{a}} \\
\frac{1}{12} \\
0 \\
0\end{array}$ & 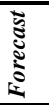 & $\stackrel{5}{5}$ & 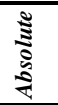 & 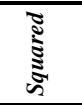 & $\begin{array}{l}\overline{2} \\
\vdots \\
0 \\
0 \\
0\end{array}$ \\
\hline \multirow{6}{*}{ ลे } & Jul & 25 & 1 & $\begin{array}{r}47 . \\
5\end{array}$ & 22.5 & 22.5 & 507.4 & 0.9 & $\begin{array}{r}25 . \\
0\end{array}$ & & & & & & & & & \\
\hline & $\begin{array}{l}A u \\
g\end{array}$ & 30 & 2 & $\begin{array}{r}46 . \\
3 \\
\end{array}$ & $16 . \overline{-}$ & 16.3 & 264.5 & 0.5 & $\begin{array}{r}25 . \\
0 \\
\end{array}$ & 5.0 & 5.0 & 25.0 & 0.2 & & & & & \\
\hline & Sep & 40 & 3 & $\begin{array}{r}45 . \\
0 \\
\end{array}$ & -5.0 & 5.0 & 25.0 & 0.1 & $\begin{array}{r}25 . \\
5 \\
\end{array}$ & 14.5 & 14.5 & 210.3 & 0.4 & & & & & \\
\hline & Oct & 75 & 4 & $\begin{array}{r}43 . \\
7\end{array}$ & 31.3 & 31.3 & 977.3 & 0.4 & $\begin{array}{r}27 . \\
0\end{array}$ & 48.1 & 48.1 & $\begin{array}{r}2308 . \\
8\end{array}$ & 0.6 & $\begin{array}{r}31 . \\
7\end{array}$ & 43.3 & 43.3 & 1877.8 & 0.6 \\
\hline & Nov & 90 & 5 & $\begin{array}{r}42 . \\
5\end{array}$ & 47.5 & 47.5 & $\begin{array}{r}2258 . \\
5\end{array}$ & 0.5 & $\begin{array}{r}31 . \\
8 \\
\end{array}$ & 58.2 & 58.2 & $\begin{array}{r}3392 . \\
5\end{array}$ & 0.6 & $\begin{array}{r}48 . \\
3\end{array}$ & 41.7 & 41.7 & 1736.1 & 0.5 \\
\hline & Dec & 50 & 6 & $\begin{array}{r}41 . \\
2\end{array}$ & 8.8 & 8.8 & 77.2 & 0.2 & $\begin{array}{r}37 . \\
6 \\
\end{array}$ & 12.4 & 12.4 & 154.3 & 0.2 & $\begin{array}{r}68 . \\
3 \\
\end{array}$ & $\begin{array}{r}- \\
18.3 \\
\end{array}$ & 18.3 & 336.1 & 0.4 \\
\hline \multirow{6}{*}{ 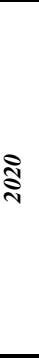 } & Jan & 18 & 7 & $\begin{array}{r}40 . \\
0 \\
\end{array}$ & $22 . \overline{-}$ & 22.0 & 481.9 & 1.2 & $\begin{array}{r}38 . \\
8 \\
\end{array}$ & $\begin{array}{r}- \\
20.8\end{array}$ & 20.8 & 433.5 & 1.2 & $\begin{array}{r}71 . \\
7 \\
\end{array}$ & $\begin{array}{r}53 . \overline{7} \\
\end{array}$ & 53.7 & 2880.1 & 3.0 \\
\hline & Feb & 35 & 8 & $\begin{array}{r}38 . \\
7 \\
\end{array}$ & -3.7 & 3.7 & 13.6 & 0.1 & $\begin{array}{r}36 . \\
7 \\
\end{array}$ & -1.7 & 1.7 & 3.0 & 0.0 & $\begin{array}{r}52 . \\
7 \\
\end{array}$ & $\begin{array}{r}- \\
17.7 \\
\end{array}$ & 17.7 & 312.1 & 0.5 \\
\hline & $\begin{array}{l}M a \\
r\end{array}$ & 15 & 9 & $\begin{array}{r}37 . \\
4 \\
\end{array}$ & $\begin{array}{r}- \\
22.4\end{array}$ & 22.4 & 503.0 & 1.5 & $\begin{array}{r}36 . \\
6 \\
\end{array}$ & $\begin{array}{r}- \\
21.6 \\
\end{array}$ & 21.6 & 465.1 & 1.4 & $\begin{array}{r}34 . \\
3 \\
\end{array}$ & $\begin{array}{r}- \\
19.3 \\
\end{array}$ & 19.3 & 373.8 & 1.3 \\
\hline & Apr & 25 & 10 & $\begin{array}{r}36 . \\
2\end{array}$ & $11 . \overline{2}$ & 11.2 & 124.7 & 0.4 & $\begin{array}{r}34 . \\
4 \\
\end{array}$ & -9.4 & 9.4 & 88.5 & 0.4 & $\begin{array}{r}22 . \\
7 \\
\end{array}$ & 2.3 & 2.3 & 5.4 & 0.1 \\
\hline & $\begin{array}{l}M a \\
y\end{array}$ & 69 & 11 & $\begin{array}{r}34 . \\
9 \\
\end{array}$ & 34.1 & 34.1 & $\begin{array}{r}1162 . \\
6 \\
\end{array}$ & 0.5 & $\begin{array}{r}33 . \\
5\end{array}$ & 35.5 & 35.5 & $\begin{array}{r}1262 . \\
5 \\
\end{array}$ & 0.5 & $\begin{array}{r}25 . \\
0 \\
\end{array}$ & 44.0 & 44.0 & 1936.0 & 0.6 \\
\hline & Jun & 15 & 12 & $\begin{array}{r}33 . \\
6 \\
\end{array}$ & $\begin{array}{r}-\overline{6} \\
\end{array}$ & 18.6 & 347.5 & 1.2 & $\begin{array}{r}37 . \\
0 \\
\end{array}$ & $22 . \overline{-}$ & 22.0 & 484.9 & 1.5 & $\begin{array}{r}36 . \\
3 \\
\end{array}$ & $\begin{array}{r}- \\
21.3 \\
\end{array}$ & 21.3 & 455.1 & 1.4 \\
\hline \multicolumn{4}{|c|}{ Total } & & 0.0 & $\begin{array}{r}243 . \\
3\end{array}$ & $\begin{array}{r}6743 . \\
1\end{array}$ & 7.7 & & 98.2 & $\begin{array}{r}249 . \\
3\end{array}$ & $\begin{array}{r}8828 . \\
4\end{array}$ & 7.1 & & 1.0 & $\begin{array}{r}261 . \\
7\end{array}$ & 9912.6 & 8.3 \\
\hline \multicolumn{4}{|c|}{ Average } & & 0.00 & $\begin{array}{r}20.2 \\
8\end{array}$ & $\begin{array}{r}561.9 \\
2\end{array}$ & $\begin{array}{r}0.6 \\
4\end{array}$ & & 8.93 & $\begin{array}{r}22.6 \\
6\end{array}$ & $\begin{array}{r}802.5 \\
8\end{array}$ & $\begin{array}{r}0.6 \\
4\end{array}$ & & 0.11 & $\begin{array}{r}29.0 \\
7\end{array}$ & $\begin{array}{r}1101.4 \\
0\end{array}$ & $\begin{array}{r}0.9 \\
3\end{array}$ \\
\hline
\end{tabular}

Sumber: Pengolahan Data

Berdasarkan Tabel 2 di atas, maka peramalan untuk Item SKU 4052899561564 untuk ke 3 metode dan grafik analisis Peramalan Item dapat dapat dilihat pada Gambar 3 dan Tabel 3 berikut ini :

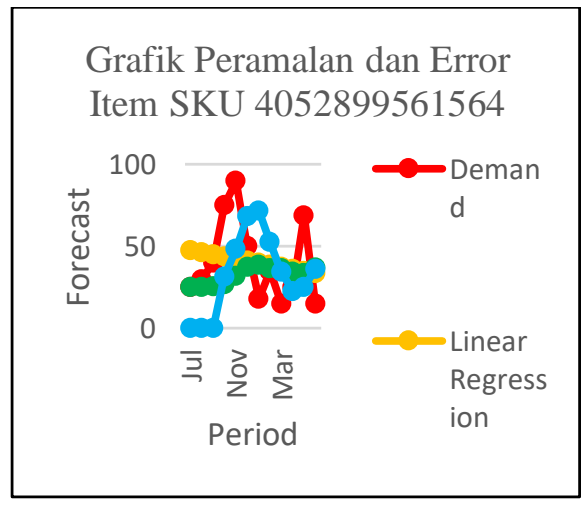

Gambar 3 Grafik Peramalan dan Error Item SKU 4052899561564
Tabel 3 Perbandingan Peramalan Item SKU 4052899561564

\begin{tabular}{|l|r|c|c|}
\hline \multicolumn{1}{|c|}{ METODE } & MA & & MAP \\
& D & MSE & E \\
\hline Linear Regression & 20.27 & 561.92 & \\
\hline Exponential & 8 & 4 & 0.641 \\
Smoothing & 22.66 & 802.58 & \\
\hline & 4 & 3 & 0.643 \\
\hline Moving Average & 29.07 & 1101.3 & \\
& 4 & 95 & 0.926 \\
\hline
\end{tabular}

Sumber: Pengolahan Data

Berdasarkan ketiga metode peramalan, peramalan yang akurasi nilai kesalahan terkecil adalah metode Linear Regression. Sehingga metode Linear Regression paling baik diantara metode lainnya. Maka untuk peramalan produk general lighting menggunakan metode Linear Regression

Selanjutnya dengan proses yang sama akan dilakukan perhitungan untuk Item SKU 4052899596221 yang dapat dilihat pada Tabel 4 , Gambar 4 dan Tabel 5 berikut ini : 
Tabel 4. Hasil Perhitungan Peramalan dan Error Item SKU 4052899596221

\begin{tabular}{|c|c|c|c|c|c|c|c|c|c|c|c|c|c|c|c|c|c|c|}
\hline \multicolumn{19}{|c|}{4052899596221} \\
\hline \multirow[b]{2}{*}{$\Xi$} & \multirow[b]{2}{*}{ 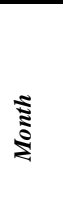 } & \multirow[b]{2}{*}{ 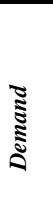 } & \multirow[b]{2}{*}{$\frac{\pi}{2}$} & \multicolumn{5}{|c|}{ Linear Regression } & \multicolumn{5}{|c|}{ Exponential Smoothing (a 0.1) } & \multicolumn{5}{|c|}{ Moving Average (3 Periode) } \\
\hline & & & & 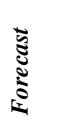 & $\stackrel{\grave{1}}{\grave{1}}$ & 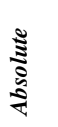 & ָัँ & 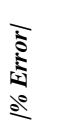 & 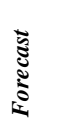 & 文 & 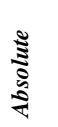 & క్ర & 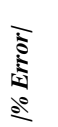 & 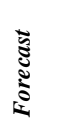 & 衣 & 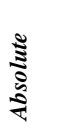 & 胥 & $\begin{array}{l}\overline{5} \\
\frac{1}{12} \\
20 \\
2\end{array}$ \\
\hline \multirow{6}{*}{ 곡 } & Jul & 22 & 1 & 47.6 & $25 . \overline{6}$ & 25.6 & $\begin{array}{r}654 . \\
8\end{array}$ & 1.2 & 22.0 & & & & & & & & & \\
\hline & Aug & 76 & 2 & 48.1 & 27.9 & 27.9 & $\begin{array}{r}775 . \\
7\end{array}$ & 0.4 & 22.0 & 54.0 & 54.0 & $\begin{array}{r}2916 \\
.0\end{array}$ & 0.7 & & & & & \\
\hline & Sep & 35 & 3 & 48.7 & $\begin{array}{r}- \\
13.7\end{array}$ & 13.7 & $\begin{array}{r}187 . \\
9\end{array}$ & 0.4 & 49.0 & $14 . \overline{-}$ & 14.0 & $\begin{array}{r}196 . \\
0\end{array}$ & 0.4 & & & & & \\
\hline & Oct & 40 & 4 & 49.3 & -9.3 & 9.3 & 85.9 & 0.2 & 42.0 & -2.0 & 2.0 & 4.0 & 0.1 & 44.3 & -4.3 & 4.3 & 18.8 & 0.1 \\
\hline & Nov & 45 & 5 & 49.8 & -4.8 & 4.8 & 23.3 & 0.1 & 41.0 & 4.0 & 4.0 & 16.0 & 0.1 & 50.3 & -5.3 & 5.3 & 28.4 & 0.1 \\
\hline & Dec & 45 & 6 & 50.4 & -5.4 & 5.4 & 29.0 & 0.1 & 43.0 & 2.0 & 2.0 & 4.0 & 0.0 & 40.0 & 5.0 & 5.0 & 25.0 & 0.1 \\
\hline \multirow{6}{*}{ હิ } & Jan & 70 & 7 & 50.9 & 19.1 & 19.1 & $\begin{array}{r}363 . \\
0\end{array}$ & 0.3 & 44.0 & 26.0 & 26.0 & $\begin{array}{r}676 . \\
0\end{array}$ & 0.4 & 43.3 & 26.7 & 26.7 & $\begin{array}{r}711 . \\
1\end{array}$ & 0.4 \\
\hline & Feb & 57 & 8 & 51.5 & 5.5 & 5.5 & 30.2 & 0.1 & 57.0 & 0.0 & 0.0 & 0.0 & 0.0 & 53.3 & 3.7 & 3.7 & 13.4 & 0.1 \\
\hline & Mar & 98 & 9 & 52.1 & 45.9 & 45.9 & $\begin{array}{r}2110 \\
.0\end{array}$ & 0.5 & 57.0 & 41.0 & 41.0 & $\begin{array}{r}1681 \\
.0\end{array}$ & 0.4 & 57.3 & 40.7 & 40.7 & $\begin{array}{r}1653 \\
.8\end{array}$ & 0.4 \\
\hline & Apr & 75 & 10 & 52.6 & 22.4 & 22.4 & $\begin{array}{r}500 . \\
7\end{array}$ & 0.3 & 77.5 & -2.5 & 2.5 & 6.3 & 0.0 & 75.0 & 0.0 & 0.0 & 0.0 & 0.0 \\
\hline & $\begin{array}{l}M a \\
y\end{array}$ & 20 & 11 & 53.2 & $33 . \overline{-}$ & 33.2 & $\begin{array}{r}1101 \\
.2\end{array}$ & 1.7 & 76.3 & $\begin{array}{r}- \\
56.3\end{array}$ & 56.3 & $\begin{array}{r}3164 \\
.1\end{array}$ & 2.8 & 76.7 & $\begin{array}{r}- \\
56.7\end{array}$ & 56.7 & $\begin{array}{r}3211 \\
.1\end{array}$ & 2.8 \\
\hline & Jun & 25 & 12 & 53.7 & $\begin{array}{r}- \\
28.7\end{array}$ & 28.7 & $\begin{array}{r}826 . \\
2\end{array}$ & 1.1 & 48.1 & 23.1 & 23.1 & $\begin{array}{r}534 . \\
8\end{array}$ & 0.9 & 64.3 & $39 . \overline{-}$ & 39.3 & $\begin{array}{r}1547 \\
.1\end{array}$ & 1.6 \\
\hline \multicolumn{4}{|c|}{ Total } & & 0.0 & $\begin{array}{r}241 . \\
4\end{array}$ & $\begin{array}{r}6687 \\
.9\end{array}$ & 6.3 & & 29.1 & $\begin{array}{r}224 . \\
9\end{array}$ & $\begin{array}{r}9198 \\
.1\end{array}$ & 5.9 & & $29 . \overline{7}$ & $\begin{array}{r}181 . \\
7\end{array}$ & $\begin{array}{r}7208 \\
.8\end{array}$ & 5.6 \\
\hline \multicolumn{4}{|c|}{ Average } & & 0.00 & $\begin{array}{r}20.1 \\
2\end{array}$ & $\begin{array}{r}557 . \\
33\end{array}$ & 0.53 & & 2.65 & $\begin{array}{r}20.4 \\
4\end{array}$ & $\begin{array}{r}836 . \\
19\end{array}$ & 0.53 & & $\begin{array}{r}- \\
3.30\end{array}$ & $\begin{array}{r}20.1 \\
9\end{array}$ & $\begin{array}{r}800 . \\
98\end{array}$ & 0.62 \\
\hline
\end{tabular}

Sumber: Pengolahan Data

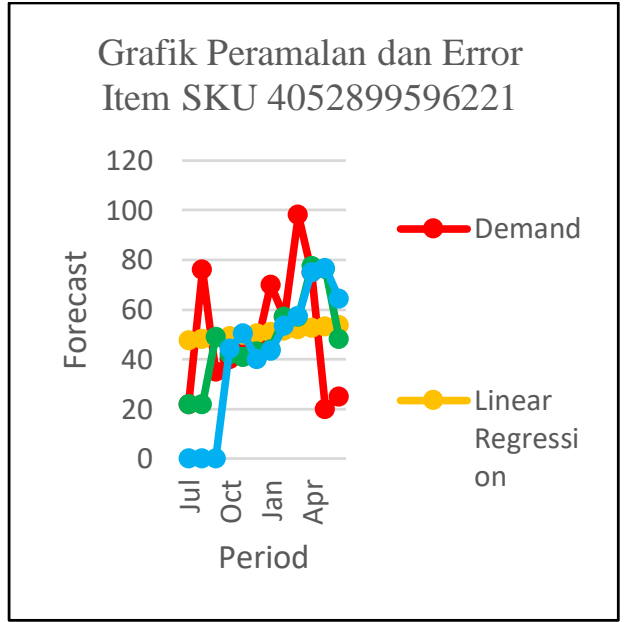

Gambar 4. Grafik Peramalan dan Error Item SKU 4052899596221
Tabel 5. Perbandingan Peramalan Item SKU 4052899596221

\begin{tabular}{|l|r|c|c|}
\hline \multicolumn{1}{|c|}{ METODE } & \multicolumn{1}{|c|}{ MA } & & MAP \\
\hline & 20.11 & MSE & E \\
\hline Linear Regression & 8 & 26 & 0.527 \\
\hline Exponential & 20.44 & 836.1 & \\
Smoothing & 3 & 89 & 0.532 \\
\hline & 20.18 & 800.9 & \\
Moving Average & 5 & 75 & 0.623 \\
\hline
\end{tabular}

Sumber: Pengolahan Data

Berdasarkan ketiga metode peramalan, peramalan yang akurasi nilai kesalahan terkecil adalah metode Linear Regression. Sehingga 
metode Linear Regression paling baik diantara metode lainnya. Maka untuk peramalan produk general lighting menggunakan metode Linear Regression. Perhitungan peramalan periode ke13 dengan menggunakan metode linear regression:

a. Item SKU 4052899561564

$$
\begin{aligned}
& Y=a+b x \\
& Y=\quad\left(\frac{\left(\sum y\right)\left(\sum x^{2}\right)-\left(\sum x\right)\left(\sum x y\right)}{n\left(\sum x^{2}\right)-\left(\sum x\right)^{2}}\right)+ \\
& \left(\frac{n\left(\sum x y\right)-\left(\sum x\right)\left(\sum y\right)}{n\left(\sum x^{2}\right)-\left(\sum x\right)^{2}}\right)(x) \\
& Y=\quad\left(\frac{(487)(650)-(78)(2985)}{(12)(650)-(78)^{2}}\right)+ \\
& \left(\frac{(12)(2985)-(78)(487)}{(12)(650)-(78)^{2}}\right)(13) \\
& Y=\left(\frac{316550-232830}{7800-6084}\right)+\left(\frac{35820-37986}{7800-6084}\right)(13) \\
& Y=\left(\frac{83720}{1716}\right)+\left(\frac{-2166}{1716}\right)(13) \\
& Y=48.7879+(-1.26224)(13) \\
& Y=48.7879+(-16.4091)=32.3788
\end{aligned}
$$

b. Item SKU 4052899596221

$$
\begin{aligned}
& Y=a+b x \\
& Y=\quad\left(\frac{\left(\sum y\right)\left(\sum x^{2}\right)-\left(\sum x\right)\left(\sum x y\right)}{n\left(\sum x^{2}\right)-\left(\sum x\right)^{2}}\right)+ \\
& \left(\frac{n\left(\sum x y\right)-\left(\sum x\right)\left(\sum y\right)}{n\left(\sum x^{2}\right)-\left(\sum x\right)^{2}}\right)(x) \\
& Y=\quad\left(\frac{(608)(650)-(78)(4032)}{(12)(650)-(78)^{2}}\right)+ \\
& \left(\frac{(12)(4032)-(78)(608)}{(12)(650)-(78)^{2}}\right)(13) \\
& Y=\quad\left(\frac{395200-314496}{7800-6084}\right)+ \\
& \left(\frac{48384-47424}{7800-6084}\right)(13) \\
& Y=\left(\frac{80704}{1716}\right)+\left(\frac{960}{1716}\right)(13) \\
& Y=47.0303+(0.55944)(13) \\
& Y=47.0303+7.27273=54.303
\end{aligned}
$$

\section{KESIMPULAN DAN SARAN}

Kesimpulan dari penelitian ini adalah :

1. Berdasarkan hasil pengolahan data permintaan dengan metode peramalan linear regression, exponential smoothing, dan moving average yang menghasilkan standart error terkecil adalah dengan metode Linear Regression sehingga yang digunakan selanjutnya untuk meramalkan permintaan untuk periode selanjutnya adalah dengan menggunakan metode Linear Regression.

2. Berdasarkan perhitungan menggunakan metode linier regression, maka didapatkan hasil peramalan untuk bulan Juli 2020 untuk ke 2 item berturut-turut adalah sebesar 32 dan 54 unit.

Saran yang dapat diberikan adalah :

1. Sebaiknya dilakukan evaluasi setiap periode untuk mengetahui item apa saja yang perlu untuk dijaga jumlah persediannya agar tidak menyebabkan keterlambatan barang untuk kebutuhan diperiode berikutnya.

2. Dari hasil analisa, sebaiknya metode peramalan yang digunakan ialah metode peramalan linier regression.

\section{DAFTAR PUSTAKA}

Adhi Kusnadi dan Jansen Pratama. 2017, Implentasi Algoritma Genetika dan Neural Network Pada Aplikasi Peramalan Produksi Mie, Jurnal ULTIMATIC 9 (1), 37-41

Aini, Q., \& Riandadari, D. 2018, Analisis Perencanaan Persediaan Spare Part Mobil Dengan Metode Abc (Konsep 80-20 ) Pada Gudang Suku Cadang Di Bengkel Pt. Liek Satu Invicta Toyota Pamekasan. Jurnal Pendidikan Teknik Mesin, 7(1), $102-108$.

Baroto, T. (2002). Perencanaan dan Pengendalian Produksi. Jakarta: Penerbit Gahlia Indonesia.

Dewi, P. S., \& Saroso, Dana. S., 2016., Implementasi Material Requirements Planning (Mrp) Pada Perencanaan Persediaan Material Panel Listrik Di Pt.Tis. Sinergi, 20(1), 36-46.

Fachrurrozi, \& Almahdy, Indra. 2015., Lot Sizing Material Requirement Planning Pada Produk Tipe Wall Mounting Di Industri Box Panel. Jurnal PASTI, X(3), 279-293.

Gasperz, Vincent. 2002. "Total Quality Management".Jakarta: PT Gramedia Pustaka Utama .

Kushartini, D., \& Almahdy, Indra. 2016., Sistem Persediaan Bahan Baku Produk Dispersant Di Industri Kimia. Jurnal PASTI, 10(2), 217-234.

Lusiana, A., \& Yuliarty, P. , 2020., Penerapan Metode Peramalan (Forecasting) Pada Permintaan Atap Di Pt X. Industri 
Inovatif: Jurnal Teknik Industri, 10(1), 11-20.

Makridakis, S., Wheelwright, S. C., \& McGee, V. E. (1999). Metode dan Aplikasi Peramalan. Jakarta: Erlangga.

Ramadhanti, L. C., \& Ariyanti, Silvi.,2017., Analisis Perencanaan Kebutuhan Material J-100 Stud Bolt \& Nuts Di Pt.
Pertamina Hulu Energi Onwj. Jurnal PASTI, XI(3), 283-299.

Sutardi, A., \& Budiasih, E. (2007). Sediakan dan Hitung stock agar tak Kehilangan Konsumen. Jakarta: Elex Media Komputindo. 